\title{
p53 and K-ras gene mutations in carcinoma of the rectum among Finnish women
}

\author{
K Servomaa, A Kiuru, V-M Kosma, P Hirvikoski, T Rytömaa
}

North Savo Regional Environment Centre, PO Box 1049, FIN-70210 Kuopio, Finland

K Servomaa

Radiation and Nuclear Safety Authority, PO Box 14, FIN-00881 Helsinki, Finland A Kiuru

Department of Environmental Sciences, University of Kuopio, PO Box 1627, FIN -70211 Kuopio,

Finland

T Rytömaa

Department of Pathology and Forensic Medicine, University of Kuopio and University

Hospital, PO Box 1627, FIN-70211 Kuopio,

Finland

P Hirvikoski

V-M Kosma

Correspondence to: Dr Servomaa

email:

kristina.servomaa@vyh.fi

Accepted for publication 4 November 1999

\begin{abstract}
Aims/Background-The aim of this study was to identify p53 and K-ras gene mutations in carcinoma of the rectum among Finnish women. Mutation patterns might give clues to aetiological factors when comparisons are made with other human tumours.

Methods-Of 134 women with carcinoma of the rectum, paraffin wax embedded specimens of the tumour tissue were obtained from 118 patients. Genomic DNA was extracted, and exons 4-8 of the p53 gene and codons $12 / 13$ and 61 of the $\mathrm{K}$-ras gene were amplified, and analysed for mutations by single strand conformation polymorphism and direct sequencing. The production of p53 and K-ras proteins was studied by immunohistochemistry.

Results-The overall crude frequency for mutations in the p53 gene was $35 \%$ but the true frequency appears to be higher (up to $56 \%$ ). In the K-ras gene, the mutation frequency $(15 \%)$ was significantly lower than that reported for colon cancer. In the p53 gene, the mutation frequency increased significantly with patient age. In a high proportion of patients $(14 \%)$ the rectal tumours contained small subclones of tumour cells that displayed extremely rare mutations at codons 110 and 232 of the p53 gene. Hot spot codon 175 mutations were significantly less common in rectal cancer than in cancer of the colon.

Conclusions-Rectal cancer among Finnish women has characteristics in the mutations of the p53 and K-ras genes that are uncommon in other human tumours, including cancer of the colon. A biological explanation of these findings is not clear at present, but might be associated with an unidentified genetic factor in Finland. (f Clin Pathol: Mol Pathol 2000;53:24-30)
\end{abstract}

Keywords: p53; K-ras; rectal carcinoma

It has been suggested that $\mathrm{p} 53$ mutations can provide clues to the nature of exogenous agents and endogenous cellular events that are important to the natural history of human cancer. ${ }^{1-4}$ However, given the complexity of most exposures, it is not surprising that at present only a few clear examples are available of an unambiguous association between a genotoxic agent and a specific mutation pattern. To reveal subtle but real differences in mutation patterns, it is necessary to accumulate detailed data on the frequency and types of mutations in various cancers and exposures. To this end, it is important that the patient groups studied can be matched for various parameters that might influence the mutation spectrum, such as age, sex, ethnicity, and geographical origin, and that relevant information is obtained of the characteristics of the tumours examined and the exposures to cancer risk factors.

The p53 tumour suppressor gene and K-ras oncogene are frequently mutated in colorectal carcinoma and are involved in the classic adenoma-carcinoma sequence. ${ }^{5}$ However, there is evidence that molecular mechanisms of colorectal carcinogenesis might differ in distinct parts of the colorectum. ${ }^{67}$ So far, little evidence is available on the molecular mechanism of rectal carcinoma, one of the leading cancer types in Finland, both among men and women. The age adjusted incidence rate (10.6/ $10^{5}$ and $6.6 / 10^{5}$ for men and women, respectively, in 1993) has been rising in all parts of the country and the trend is expected to continue. ${ }^{8}$ Because the risk factors in rectal and colon cancers are partly similar (for example, a diet rich in fat) and partly different (for example, dietary calcium, reproductive factors, and low physical activity are associated with the risk of colon cancer but not of rectal cancer), ${ }^{9}{ }^{10}$ it is possible that mutations in the p53 and K-ras genes are not similar in these tumours.

We have examined a group of 118 Finnish women with cancer of the rectum for $\mathrm{p} 53$ and K-ras mutations. In addition to expressing the results in relation to different group parameters, such as patient age, we have, as far as possible, compared the mutation frequencies and patterns with those compiled from the literature. Furthermore, from the same group of patients we also analysed the production of p53 and K-ras proteins.

\section{Methods and materials}

PATIENTS

The study comprised 134 women with carcinoma of the rectum diagnosed in Finland in 1963-1992. Half of the patients had received radiotherapy for cervical carcinoma $\geqslant 10$ years earlier; the other half, matched for age and year of diagnosis, had no history of unusual radiation exposure. With regard to the effects of radiotherapy on $\mathrm{K}$-ras and p53 mutations in secondary cancers, detailed results will be published elsewhere. For the purposes of our present study, it is important to note that the pooled data are not likely to misrepresent K-ras and p53 mutation patterns for primary cancer of the rectum. The reason is that in radiation induced cancers K-ras and p53 mutations are very rare, ${ }^{11}$ and therefore they cannot modify the mutation patterns significantly. The only 
notable effect is on the crude point estimate of the mutation frequency (see Results).

Of the initial group of 134 patients, a paraffin wax embedded specimen of the tumour tissue was obtained from 118 patients (88\%) from the pathological archives of Finnish hospitals. All samples were subjected to re-evaluation of the original histological diagnosis by an expert pathologist (V-MK), who also selected representative tissue section areas for DNA extraction and further molecular analyses.

PREPARATION OF GENOMIC DNA

For DNA extraction, one to three paraffin wax embedded 5-30 $\mu \mathrm{m}$ sections were dewaxed with two treatments in xylene and rehydrated. The pieces of material were broken up in TE (10 mM Tris, $1 \mathrm{mM}$ EDTA, pH 8.0). Proteinase $\mathrm{K}$ in $10 \%$ sodium dodecyl sulphate was added to a final concentration of $1 \mathrm{mg} / \mathrm{ml}$ and the samples were digested overnight at $60^{\circ} \mathrm{C}$. The samples were then heated to $95^{\circ} \mathrm{C}$ for 10 minutes, cooled on ice, extracted by phenol/ chloroform/isoamyl alcohol, and precipitated overnight with $10 \mathrm{M}$ ammonium acetate, glycogen, and ethanol at $-20^{\circ} \mathrm{C}$. The DNA pellets were washed twice with $70 \%$ ethanol, dried, and resuspended in $30-50 \mu \mathrm{l}$ of TE ( $\mathrm{pH}$ 8.0). Aliquots containing $60 \mathrm{ng}$ of DNA were used for the polymerase chain reaction (PCR).

POLYMERASE CHAIN REACTION

Exons $4-8$ of the p53 gene, and codons $12 / 13$ and 61 of the K-ras gene, were individually amplified by PCR using different primer pairs flanking the exons and codons of interest. Exons 5-8 of the p53 gene, and codons 12/13 and 61 of the K-ras gene, were amplified as one fragment each, whereas exon 4 of the p53 gene was split into two fragments for amplification. The following primers and annealing temperatures were used for PCR.

(1) p53 exon 4:5': 5'-GTCCTCTGACTG CTCTTTTC-3' (sense) and 5'-CTGCC CTGGTAGGTTTTCTG-3' (antisense); annealing temperature $56^{\circ} \mathrm{C}$.

(2) p53 exon 4:3': 5'-GCACCAGCAGCT CCTACACC-3' (sense) and 5'-CGGCC AGGCATTGAAGTCTC-3' (antisense); annealing temperature $58^{\circ} \mathrm{C}$.

(3) p53 exon 5: 5'-TGTGCCCTGACT TTCAACTC-3' (sense) and 5'-ACCAGC CCTGTCGTCTCTCC-3' (antisense); annealing temperature $58^{\circ} \mathrm{C}$.

(4) p53 exon 6: 5'-TCCTCACTGATT GCTCTT-3' (sense) and 5'-CACATC TCATGGGGTTAT-3' (antisense); annealing temperature $53^{\circ} \mathrm{C}$.

(5) p53 exon 7: 5'-TCATCTTGGGCC TGTGTTAT-3' (sense) and 5'-AGGTGG ATGGGTAGTAGTAT-3' (antisense); annealing temperature $53^{\circ} \mathrm{C}$.

(6) p53 exon 8: 5'-TGCTTCTCTTTT CCTATCCT-3' (sense) and 5'-TTGTCC TGCTTGCTTACCTC-3' (antisense); annealing temperature $53^{\circ} \mathrm{C}$.

(7) K-ras codons 12/13: 5'-CTGCTGAAAA TGACTGAATA-3' (sense) and 5'-ATGG
TCCTGCACCAGTAATA-3' (antisense); annealing temperature $48^{\circ} \mathrm{C}$.

(8) K-ras codon 61: 5'-CCTTCTCAGGAT TCCTACAG-3' (sense) and 5'-TTATTT ATGGCAAATACACA-3' (antisense); annealing temperature $49^{\circ} \mathrm{C}$.

The PCR reaction mix $(100 \mu \mathrm{l})$ consisted of $1 \times$ Dynazyme buffer, $200 \mu \mathrm{M}$ dNTPs, 2 units Dynazyme DNA polymerase (Finnzymes, Espoo, Finland), $0.4 \mu \mathrm{M}$ primers, and $60 \mathrm{ng}$ template DNA. Amplification was performed on a Perkin Elmer Cetus GeneAmp2400 (Perkin Elmer Cetus, Branchburg, New Jersey, USA) using conditions optimised for each exon. PCR samples were denatured at $94^{\circ} \mathrm{C}$ for five minutes and subjected to 40 cycles at $94^{\circ} \mathrm{C}$ for one minute, $48-58^{\circ} \mathrm{C}$ for one minute, and $72^{\circ} \mathrm{C}$ for one minute. A final extension step at $72^{\circ} \mathrm{C}$ for seven minutes was performed, after which the samples were cooled to $4^{\circ} \mathrm{C}$. The sizes of the PCR products were $253 \mathrm{bp}$ (p53 exon 4:5'), 199 bp (p53 exon 4:3'), 262 bp (p53 exon 5), 259 bp (p53 exon 6), 251 bp (p53 exon 7), 180 bp (p53 exon 8), 162 bp (K-ras codons 12/13), and $155 \mathrm{bp}$ (K-ras codon 61).

SINGLE STRAND CONFORMATION POLYMORPHISM (SSCP)

Mutation screening was performed using SSCP analysis. The PCR products were purified from low melting point agarose using PCR Preps DNA purification resin (Promega, Madison, USA) and isopropanol precipitation. PCR products $(2 \mu \mathrm{l})$ were denatured for 10 minutes at $96^{\circ} \mathrm{C}$ with $2 \mu \mathrm{l}$ of formamide denaturing dye mixture (94\% formamide, $10 \mathrm{mM}$ EDTA, $0.3 \%$ xylene cyanol, and $0.3 \%$ bromophenol blue), cooled on ice, and then applied ( $4 \mu 1 /$ lane) to precast Phast gel polyacrylamide minigels (Pharmacia Biotech, Uppsala, Sweden). Electrophoresis of the minigels was performed on the Phast gel electrophoresis system using two different gels and electrophoresis conditions optimised for each exon. Minigels were silver stained according to the manufacturer's protocol, and vacuum dried between two sheets of cellophane. DNA showing an altered mobility, distinct from that of a normal band in SSCP analysis, was analysed further by direct sequencing.

DIRECT DNA SEQUENCING

To verify SSCP suggested mutations, direct sequencing of both strands of the purified PCR products was performed using the same primers as in the PCR. Applied Biosystems prism dye deoxy terminator sequencing kit and the automatic ABI 373 DNA sequencer were used, according to the manufacturer's protocol (Applied Biosystems). The identified mutations were confirmed by a separate PCR and subsequent sequence analysis.

IMMUNOHISTOCHEMISTRY

The tumour specimens adjacent to those used to determine p53 and K-ras gene mutations were analysed by immunohistochemistry for the presence of p53 and K-ras proteins. Immunohistochemical staining using the 
Table 1 p53 mutations among 118 female patients with carcinoma of the rectum

\begin{tabular}{|c|c|c|c|c|}
\hline \multirow{2}{*}{$\frac{\text { Patient }}{\text { RE110 }}$} & \multirow{2}{*}{$\begin{array}{l}\text { Exon:codon } \\
4: 100\end{array}$} & \multicolumn{2}{|l|}{ Mutation } & \multirow{2}{*}{$\begin{array}{l}\text { IHC (DO-7) } \\
+\end{array}$} \\
\hline & & $\mathrm{CAG} \rightarrow \mathrm{CGG}$ & $\mathrm{Gln} \rightarrow \mathrm{Arg}$ & \\
\hline RE52 & $4: 110$ & $\mathrm{CGT} \rightarrow \mathrm{TGT}$ & $\mathrm{Arg} \rightarrow \mathrm{Cys}$ & + \\
\hline RE61* & $4: 110$ & $\mathrm{CGT} \rightarrow \mathrm{TGT}$ & Arg $\rightarrow$ Cys & + \\
\hline RE66 & $4: 110$ & $\mathrm{CGT} \rightarrow \mathrm{TGT}$ & Arg $\rightarrow$ Cys & + \\
\hline RE119* & $4: 110$ & $\mathrm{CGT} \rightarrow \mathrm{TGT}$ & $\mathrm{Arg} \rightarrow \mathrm{Cys}$ & - \\
\hline RE116 & $5: 140-144$ & \multicolumn{2}{|c|}{ Deletion 14 bp (CCTGCCCTGTGCAG) } & NT \\
\hline RE4 & $5: 151$ & $\mathrm{CCC} \rightarrow \mathrm{TCC}$ & $\mathrm{CCC} \rightarrow \mathrm{TCC}$ & + \\
\hline RE42 & $5: 167$ & $\mathrm{CAG} \rightarrow \mathrm{TAG}$ & $\mathrm{Gln} \rightarrow \mathrm{STOP}$ & - \\
\hline RE58 & $5: 175$ & $\mathrm{CGC} \rightarrow \mathrm{CAC}$ & Arg $\rightarrow$ His & + \\
\hline RE129* & $5: 175$ & $\mathrm{CGC} \rightarrow \mathrm{CAC}$ & $\mathrm{Arg} \rightarrow \mathrm{His}$ & + \\
\hline $\mathrm{RE} 41^{\star}$ & $5: 176$ & $\mathrm{TGC} \rightarrow \mathrm{TGA}$ & Cys $\rightarrow$ STOP & - \\
\hline RE127* & $5: 176$ & \multicolumn{2}{|c|}{ Deletion 2 bp (GC) } & - \\
\hline RE37^ & $5: 179$ & $\mathrm{CAT} \rightarrow \mathrm{CGT}$ & $\mathrm{His} \rightarrow \mathrm{Arg}$ & + \\
\hline RE38 & $5: 181$ & $\mathrm{CGC} \rightarrow \mathrm{CCC}$ & Arg $\rightarrow$ Pro & + \\
\hline RE69* & $6: 188-196$ & \multicolumn{2}{|c|}{ Deletion 28 bp (CGGATAAGATGCTGAGGAGGGGCCAGAC) } & + \\
\hline RE12 & $6: 214-215$ & \multicolumn{2}{|c|}{ Deletion 2 bp (TA) } & - \\
\hline RE86 & $6: 216$ & GTG $\rightarrow$ TTG & Val $\rightarrow$ Leu & + \\
\hline RE73* & $7: 232$ & $\mathrm{ATC} \rightarrow \mathrm{AAC}$ & $\mathrm{Ile} \rightarrow$ Asn & + \\
\hline RE72 & $7: 235$ & \multicolumn{2}{|c|}{ Insertion 9 bp (TTCCTTACA) } & + \\
\hline RE36 & $7: 236$ & $\mathrm{TAC} \rightarrow \mathrm{AAC}$ & Tyr $\rightarrow$ Asn & + \\
\hline RE65* & $7: 245$ & $\mathrm{GGC} \rightarrow \mathrm{AGC}$ & Gly $\rightarrow$ Ser & + \\
\hline RE67* & $7: 245$ & $\mathrm{GGC} \rightarrow \mathrm{AGC}$ & Gly $\rightarrow$ Ser & + \\
\hline RE76 & $7: 245$ & GGC $\rightarrow$ AGC & Gly $\rightarrow$ Ser & NT \\
\hline RE104 & $7: 245$ & GGC $\rightarrow$ AGC & Gly $\rightarrow$ Ser & + \\
\hline RE6 & $7: 248$ & $\mathrm{CGG} \rightarrow \mathrm{CAG}$ & Arg $\rightarrow$ Gln & + \\
\hline RE44 & $7: 248$ & $\mathrm{CGG} \rightarrow \mathrm{TGG}$ & Arg $\rightarrow \operatorname{Trp}$ & + \\
\hline RE82 & $7: 248$ & $\mathrm{CGG} \rightarrow \mathrm{TGG}$ & Arg $\rightarrow$ Trp & + \\
\hline RE103* & $7: 250$ & \multicolumn{2}{|c|}{ Deletion $2 \mathrm{bp}(\mathrm{CC})$} & - \\
\hline RE74 & $7: 254$ & \multirow{2}{*}{\multicolumn{2}{|c|}{ Insertion 9 bp (AATCTACTG) }} & + \\
\hline RE28 & $8: 263-265$ & & & + \\
\hline RE56 & $8: 270$ & $\mathrm{TTT} \rightarrow \mathrm{CTT}$ & Phe $\rightarrow$ Leu & + \\
\hline RE2 & $8: 273$ & $\mathrm{CGT} \rightarrow \mathrm{AGT}$ & Arg $\rightarrow$ Ser & + \\
\hline RE49* & $8: 273$ & $\mathrm{CGT} \rightarrow \mathrm{CAT}$ & Arg $\rightarrow$ His & NT \\
\hline RE57* & $8: 273$ & $\mathrm{CGT} \rightarrow \mathrm{CAT}$ & $\mathrm{Arg} \rightarrow \mathrm{His}$ & + \\
\hline RE99* & $8: 273$ & $\mathrm{CGT} \rightarrow \mathrm{TGT}$ & Arg $\rightarrow$ Cys & + \\
\hline RE134 & $8: 273$ & $\mathrm{CGT} \rightarrow \mathrm{TGT}$ & Arg $\rightarrow$ Cys & + \\
\hline RE130 & $8: 273$ & Duplication 25 & अTTTGTGCCTGTCCTGGGAGAGA) & - \\
\hline RE64 & $8: 277$ & $\mathrm{TGT} \rightarrow \mathrm{TTT}$ & Cys $\rightarrow$ Phe & + \\
\hline RE7* & $8: 282$ & $\mathrm{CGG} \rightarrow \mathrm{TGG}$ & $\operatorname{Arg} \rightarrow \operatorname{Trp}$ & + \\
\hline RE24 & $8: 282$ & $\mathrm{CGG} \rightarrow \mathrm{TGG}$ & Arg $\rightarrow$ Trp & + \\
\hline RE112 & $8: 306$ & $\mathrm{CGA} \rightarrow \mathrm{TGA}$ & Arg $\rightarrow$ STOP & - \\
\hline
\end{tabular}

*Second carcinoma after radiotherapy of cervical cancer (see Methods).

$\mathrm{ICH}$, immunohistochemical staining of formalin fixed, paraffin wax embedded section of the tumours with DO-7 anti-p 53 antibody; ,$-<20 \%$ positive nuclei;,$+ \geqslant 20 \%$ positive nuclei; NT, not tested.

monoclonal antibody DO-7 (DAKO, Glostrup, Denmark) for p53, and the monoclonal antibody F-234 (Santa Cruz Biotechnology, Santa Cruz, California, USA) for K-ras, was performed on formalin fixed, paraffin wax embedded preparations of histologically confirmed adenocarcinoma of the rectum. Tumour sections ( $5 \mu \mathrm{m}$ thick) were dewaxed, rehydrated, and washed with phosphate buffered saline (PBS; $\mathrm{pH} 7.2$ ). After boiling in $0.01 \mathrm{M}$ citrate buffer ( $\mathrm{pH}$ 6.0) two to five times for five minutes each in a microwave, the sections were cooled for 15 minutes in $0.05 \mathrm{M}$ Tris buffered saline ( $\mathrm{pH}$ 7.4) and then washed twice in PBS. Endogenous peroxidase activity was blocked by $5 \%$ hydrogen peroxide in water for five minutes, followed by washing for five minutes with PBS. The tissue sections were incubated overnight at $4^{\circ} \mathrm{C}$ with the primary antibody (DO-7 or F-234) diluted $1 / 500$ or $1 / 10$, respectively, in PBS with $1 \%$ bovine serum albumin. Sections were washed twice with PBS and incubated for 30 minutes with biotinylated secondary antibody (ABC Vectastain mouse elite kit) $1 / 200$ in PBS. Slides were washed twice in PBS for five minutes and incubated for 40 minutes in preformed avidin biotinylated peroxidase complex. Sections were washed twice for five minutes with PBS, developed with diaminobenzidine tetrahydrochloride substrate, lightly counterstained with Mayer's haematoxylin, dehydrated, cleared, and mounted. A p53 positive colon adenocar- cinoma sample was used as a positive control. For immunohistochemical analyses, tumours with $\geqslant 20 \%$ positive cells were scored as overproducing the protein (p53 or K-ras, respectively).

All specimens were analysed, unaware of the results of the mutation analysis, by two observers (V-MK, PH) simultaneously and a consensus was reached.

\section{Results}

DETECTION OF 553 GENE MUTATIONS

Exons $4-8$ of the p53 gene were studied in 118 patients with carcinoma of the rectum. All exons were not amplifiable in all patients. Amplification of exon 4 was successful in 106 patients, exon 5 in 109 patients, exon 6 in 92 patients, and exons 7 and 8 in 104 patients. Of the 118 patients, $41(35 \%)$ had a p53 mutation. A refined estimation of the mutation frequency is presented below. Table 1 shows the exact nature of the p53 mutations detected. Mutations that were successfully repeated from a new template DNA are given in this table; mutations possibly associated with tumour mosaicism are dealt with later in the text.

The distribution of different types of p53 mutations shown in table 1 was compared with the data base of human colon and rectum cancers. ${ }^{4}$ In our samples, deletions and insertions were significantly $(\mathrm{p}<0.01)$ more common than in the data base for colon cancer 
Table 2 Distribution of p53 mutation types in rectal and colorectal carcinomas

\begin{tabular}{llllll}
\hline & \multicolumn{2}{l}{ Rectal } & & \multicolumn{2}{c}{ Colorectal } \\
\cline { 2 - 3 } \cline { 6 - 6 } p53 mutation type & $n$ & $\%$ & & & $\%$ \\
\hline G:C $\rightarrow$ A:T at CpG & 20 & 49 & & 277 & 49 \\
G:C $\rightarrow$ A:T at non-CpG & 2 & 5 & & 95 & 17 \\
G:C $\rightarrow$ C:G & 1 & 2 & & 16 & 3 \\
G:C $\rightarrow$ T:A & 4 & 10 & & 54 & 9 \\
A:T $\rightarrow$ C:G & 0 & 0 & & 10 & 2 \\
A:T $\rightarrow$ G:C & 3 & 7 & & 47 & 8 \\
A:T $\rightarrow$ T:A & 3 & 7 & & 24 & 4 \\
Deletions, insertions, complex & 8 & 20 & & 45 & 8 \\
Total & 41 & & & 568 &
\end{tabular}

Non-confirmed codon 110 and 232 mutations (possible tumour mosaicism, see text) are excluded.

Rectal results are from this study; colorectal results are from Hainaut $e t$ al. $^{4}$

(table 2); differences in transition/transversion frequencies were not significant.

The frequently affected codons were, as expected, the hot spot codons $175,245,248$, 273, and 282 (table 1). Figure 1 shows the distribution of p53 mutations in these codons in our series and in the current data base of human colon cancers. ${ }^{4}$ Owing to the small number of mutations in each hot spot codon, our material was combined with other rectal cancers (combined frequencies are indicated by open circles in the figure) recorded in the current data base. ${ }^{4}$ Overall, codon 175 mutations are less common $(\mathrm{p}<0.05)$ in rectal cancer than in colon cancer (five of $123 v 107$ of 980, including rectosigmoid cancer).

In 10 patients (10 of $118 ; 8.5 \%$ ) a $\mathrm{C} \rightarrow \mathrm{T}$ transition at a $\mathrm{CpG}$ site was observed at codon 110 (CGT) which is, judging from published data compilations, ${ }^{4}$ very rarely mutated in human tumours (16 of 9378; $2 \%$, with only four $\mathrm{C} \rightarrow \mathrm{T}$ transitions). In one of these 10 patients, the mutation was confirmed by repeating the analysis from a new DNA template; in three patients, the repeat analysis was successful from the original DNA template but not from a new sample (these four patients are included in table 1). In six cases where insufficient original DNA template was available for repeat analysis, codon 110 mutation was not detected from new DNA samples. In two of the 10 patients with a codon 110 mutation, another p53 mutation was also present (a

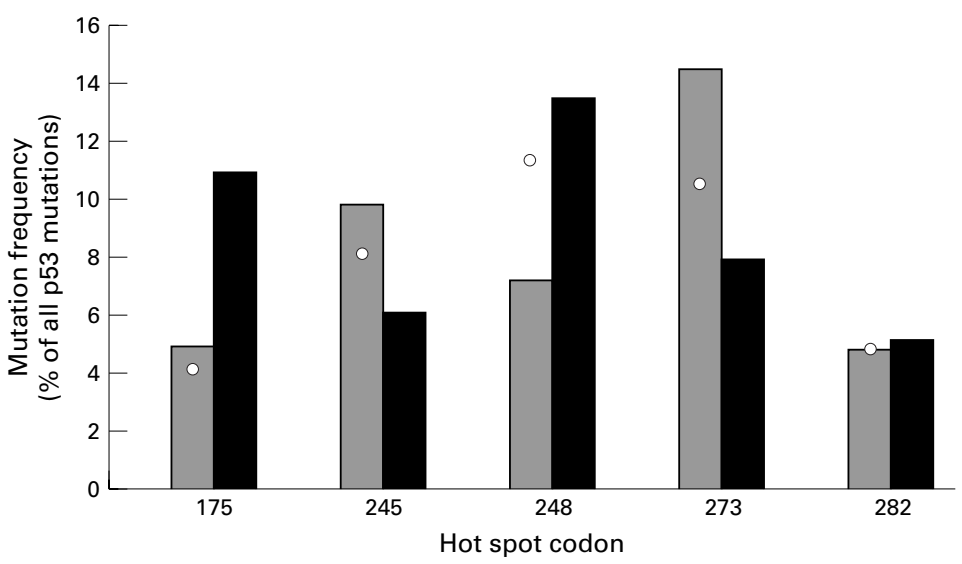

Figure 1 Frequency of p53 mutations in five hot spot codons in rectal cancer among Finnish women and in colon cancer (current data base ${ }^{4}$ ). The open circles represent frequencies for rectal cancer in combined material (our study plus the current data base with specified rectal cancer). Hatched columns, rectal cancers; filled columns, colon cancers.
Table 3 Distribution of p53 gene mutations by age at diagnosis of female patients with cancer of the rectum

\begin{tabular}{lll}
\hline Age group (years) & Patients & Mutations \\
\hline $50-9$ & 17 & $2(3)$ \\
$60-9$ & 36 & $10(14)$ \\
$70-9$ & 49 & $21(24)$ \\
$80-9$ & 16 & $8(11)$ \\
Total & 118 & $41(52)$ \\
\hline
\end{tabular}

The values in parenthesis include codon 110 and 232 mutations that could not be confirmed by repeated sequence analysis (probable tumour mosaicism, see text).

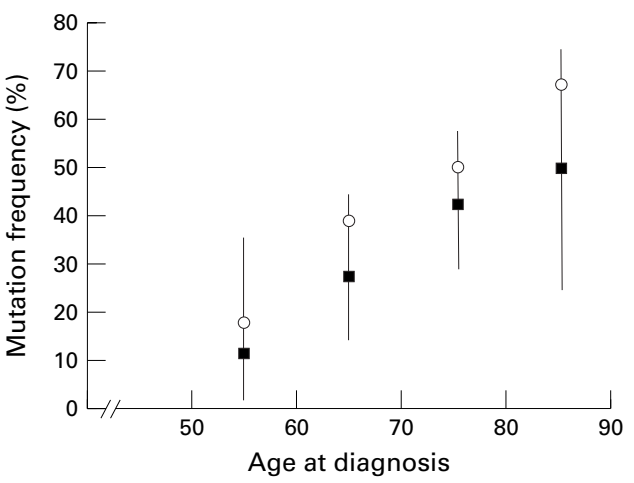

Figure 2 Frequency of p53 gene mutations in different age groups in female patients with cancer of the rectum.

Observed frequencies and $95 \%$ confidence limits are shown. The open circles represent frequencies when apparent mosaic cases are included (table 3).

$2 \mathrm{bp}$ deletion at codon $214-215$ in patient $\mathrm{RE} 86$, and a $\mathrm{C} \rightarrow \mathrm{T}$ transition at codon 273 in patient RE99).

The possible presence of mosaicism in human rectal cancers was supported by the finding of seven patients with a $\mathrm{T} \rightarrow \mathrm{A}$ transversion at codon 232 (ATC), which again is a rarely mutated codon in human tumours (30 of $9378 ; 0.3 \%$, with only five $\mathrm{T} \rightarrow \mathrm{A}$ transversions $\left.{ }^{4}\right)$. In our seven patients, the mutation was confirmed in one patient (RE73) from the original DNA template. Of the remaining six patients, the amount of original DNA template was insufficient for repeat analysis; analysis of new DNA samples revealed the wild-type p53 sequence.

p53 MUTATION FREQUENCY

Table 3 gives the absolute number of p53 mutations detected, grouped according to the age of the patient at diagnosis; the frequencies are shown in fig 2 . The mean age of our group of patients was 70.0 years (range, 52-89), which is identical to the mean age of all female patients with cancer of the rectum diagnosed in Finland in 1980-1986. ${ }^{12}$

As already indicated, the crude overall frequency of p53 mutations in our material was 41 of 118 (table 1) or 35\% (95\% confidence limits, $26 \%$ to $43 \%$ ). This value is likely to be an underestimate of the true frequency for primary cancers of the rectum, because a quarter of the cancers in our series were radiation induced, with a low incidence of $\mathrm{p} 53$ mutations (see above). ${ }^{11}$ Among the 62 non-irradiated patients, the frequency of p53 mutations was 26 of $62(42 \%)$. Furthermore, these estimates do not include codon 110 and 232 mutations that could not be confirmed by repeated sequencing (probable tumour mosaicism, see 
Table 4 K-ras mutations in 118 female patients with cancer of the rectum

\begin{tabular}{|c|c|c|c|c|}
\hline Patient & Codon & Mutation & & $I H C(F-234)$ \\
\hline RE43* & 12 & GGT $\rightarrow$ GAT & Gly $\rightarrow$ Asp & NT \\
\hline RE78 & 12 & GGT $\rightarrow$ GAT & Gly $\rightarrow$ Asp & + \\
\hline RE86 & 12 & $\mathrm{GGT} \rightarrow \mathrm{GAT}$ & $\mathrm{Gly} \rightarrow \mathrm{Asp}$ & + \\
\hline RE108 & 12 & $\mathrm{GGT} \rightarrow \mathrm{GAT}$ & Gly $\rightarrow$ Asp & NT \\
\hline RE23* & 12 & $\mathrm{GGT} \rightarrow \mathrm{TGT}$ & Gly $\rightarrow$ Cys & NT \\
\hline RE112 & 12 & $\mathrm{GGT} \rightarrow \mathrm{TGT}$ & Gly $\rightarrow$ Cys & + \\
\hline RE126 & 12 & $\mathrm{GGT} \rightarrow \mathrm{TGT}$ & Gly $\rightarrow$ Cys & + \\
\hline RE58 & 12 & GGT $\rightarrow$ GTT & Gly $\rightarrow$ Val & - \\
\hline RE124 & 12 & GGT $\rightarrow$ GTT & Gly $\rightarrow$ Val & + \\
\hline RE69* & 12 & $\mathrm{GGT} \rightarrow \mathrm{GCT}$ & Gly $\rightarrow$ Ala & + \\
\hline RE99* & 12 & $\mathrm{GGT} \rightarrow \mathrm{GCT}$ & $\mathrm{Gly} \rightarrow \mathrm{Ala}$ & + \\
\hline RE36 & 12 & Duplication $3 \mathrm{bp}$ & & + \\
\hline RE38 & 13 & $\mathrm{GGC} \rightarrow \mathrm{GAC}$ & Gly $\rightarrow$ Asp & + \\
\hline RE82 & 13 & $\mathrm{GGC} \rightarrow \mathrm{GAC}$ & Gly $\rightarrow$ Asp & + \\
\hline RE2 & 61 & $\mathrm{CAA} \rightarrow \mathrm{CAC}$ & Gly $\rightarrow$ His & + \\
\hline RE24 & 61 & $\mathrm{CAA} \rightarrow \mathrm{CAC}$ & Gly $\rightarrow$ His & + \\
\hline
\end{tabular}

*Second carcinoma after radiotherapy of cervical cancer. $\mathrm{ICH}$, immunohistochemical staining of formalin fixed, paraffin wax embedded section of tumours with F-234 anti-K-ras antibody;,$-<20 \%$ positive nuclei;,$+ \geqslant 20 \%$ positive nuclei; NT, not tested.

above). If these mutations are included, the overall p53 mutation frequency is 52 of 118 $(44 \%)$, or 35 of $62(56 \%)$ if computed from the non-irradiated patient group.

DETECTION OF K-ras GENE MUTATIONS

Codons 12/13 and 61 of the K-ras gene were studied in the same 118 patients analysed for p53 mutations. The two K-ras exons were not amplifiable in all patients. Amplification of the first exon was successful in 109 patients, as was amplification of the second exon in 96 patients. Of the 118 patients, 16 had K-ras mutations (table 4). This mutation frequency $(14 \%)$ is significantly $(\mathrm{p}<0.001)$ lower than the usually detected mutation frequency of about $50 \%$ in colorectal carcinoma. ${ }^{13-16}$

Ten of the 16 patients with K-ras mutations also had mutations in the p53 gene. The ratio increases to 12 of 16 if apparent tumour mosaicism (mutation in codon 110 or 232 of the p53 gene) is included. This coupling between K-ras and p53 mutation is significant $(\mathrm{p}<0.01)$.

\section{IMMUNOHISTOCHEMISTRY}

Immunohistochemical staining of the p53 protein was strong in 30 patients, and low or absent in eight patients with p53 mutations (table 1). In seven of these eight patients the mutated protein was apparently truncated (three stop codon mutations and four frameshifts; table 1). Overall, in two patients immunohistochemical staining and the p53 mutation status gave a conflicting result (table 1): in patient RE119 staining for p53 protein was weak in spite of the confirmed mutation at codon 110, and in patient RE69 it was strong in spite of a frameshift causing deletion.

With respect to immunohistochemistry of the K-ras gene, 12 of the 13 cases studied gave the result expected: K-ras mutation was associated with strong staining for the protein (table 4). In one patient (RE58), immunohistochemistry did not reveal overproduction of the K-ras protein, in spite of a confirmed mutation at codon 12 ( $\mathrm{G} \rightarrow \mathrm{T}$ transversion).

\section{Discussion}

Our study, based on an analysis of a group of 118 Finnish women with cancer of the rectum, reveals mutation patterns in the p53 gene that are not seen in patients with cancer of the colon, judging by the compiled data base. ${ }^{4}$ In particular, we saw a strong and significant positive correlation between patient age at diagnosis and the frequency of p53 mutation (fig 2). However, we cannot offer any single plausible explanation for this association, such as a difference in exposure to a specific carcinogen, age dependent differences in DNA repair, or age dependent alterations in bioselection processes. Another study of this patient group indicated that older patients had significantly shorter survival time than did younger patients. ${ }^{17}$ However, p53 mutations were not associated with survival. We suggest from these findings that p53 mutation is not an indicator of a clinically aggressive rectal cancer, as it may be in colon cancer. ${ }^{18}$

Another surprising finding of our study was the unexpected frequency of codon 110 and 232 mutations. In particular, four of the 41 $(10 \%)$ confirmed mutations were detected at codon 110 ( $\mathrm{C} \rightarrow \mathrm{T}$ transition at a $\mathrm{CpG}$ site). Including the additional six similar mutations seen at codon 110, which probably reflect tumour mosaicism and could not be repeated using a new DNA sample from the same tumour, the frequency of codon 110 mutations might be as high as 10 of $52(19 \%)$. This frequency contrasts greatly with the frequency seen in the data compilation of human tumours. ${ }^{4}$ Codon 110 mutations in rectal cancers among Finnish women are 100-fold greater than in human tumour material in general. Similar results were found at codon 232, where the mutation frequency was as high as seven of $52(13 \%)$. Thus, the frequency of codon 232 mutations in Finnish woman with rectal cancer might also be 100 -fold greater than in human tumour material overall. ${ }^{4}$

One possible explanation for these findings is that for some unknown reason our high frequencies of codon 110 and 232 mutations are an artefact arising - for example, from contamination at the time of sectioning. However, the artefact hypothesis is complicated because in the four tumours where enough original DNA template was available for a new analysis, independent PCR and direct sequencing confirmed the earlier finding. Furthermore, in one of the 12 cases where the original DNA template was insufficient for a repeat analysis, a new DNA sample extracted from new tumour tissue sections revealed the same mutation. Possible contamination at the time of sectioning is also unlikely on the grounds that the appearance of the "contaminants" was not clustered, but was distributed more or less randomly between the block groups sectioned at different times. It is also worth noting that we have previously analysed hundreds of different types of human tumours for p53 mutations, but have only seen one mutation at each of codons 110 and 232 (both mutations were in the same tumour cell line, established from a tongue carcinoma ${ }^{19}{ }^{20}$ ). Thus, the frequency 
detected by us in non-rectal human cancers is similar to the frequency seen in the current data base, which suggests that our methodology does not have an unidentified inherent error that leads to artefactual detection of codon 110 and 232 mutations.

Apart from codon 110 and 232 mutations, our results do not indicate drastic differences in the p53 mutation spectra between Finnish women with cancer of the rectum and the compiled human data base of colon cancer (fig 1). For example, judging from the p53 mutation types shown in table 2, the only apparent difference seems to be the higher deletion/insertion frequency recorded by us compared with that present in the compiled data base. Even this difference might be partly artefactual because it is possible that small insertions or deletions are underreported in the literature, owing to difficulties in sequence reading. This is because superimposed mutated and wild-type sequences might sometimes be considered as technical artefacts, especially when sequence reading is based on visual recording of an autoradiogram. The relative frequency of mutations in the five hot spot codons $(175,245,248,273$, and 282) in our rectal cancer samples appeared to be different to that recorded in the data base for colon cancer (fig 1). However, according to statistical analysis, the frequency difference between rectal and colon cancers was significant only for codon 175 mutations.

With respect to K-ras mutations in cancer of the rectum, the frequency was significantly lower in our material than that reported in the literature for colorectal cancer $(15 \%$ v $50 \%{ }^{2122}$ ). This difference in frequency may be explained, in part, by the fact that about a quarter of our patients had a radiation induced tumour (see Methods and materials), and in these tumours K-ras mutations are very rare. ${ }^{11}$ However, a significant difference still remains when the analysis is limited to the group where the patients had no history of unusual radiation exposure (among these patients the frequency was 12 of $55 ; 22 \%$ ). These low mutation frequencies suggest that in rectal cancer K-ras mutation is not a common early event in carcinogenesis, as is believed to be the case in colorectal cancer. ${ }^{14}{ }^{23}$ Consequently, we suggest also on this basis that the aetiological factors in cancers of the rectum and colon are likely to be different.

Immunohistochemistry for p53 and K-ras protein production, studied in 51 samples from the patients with a p53 or K-ras mutation present, gave the expected results. The overall agreement was 48 of 51 (94\%); that is, a positive reaction was detected in patients with a K-ras or p53 point mutation, and a negative reaction was found in patients with truncated p53 protein. Furthermore, in one of the three cases where the immunohistochemical staining result did not agree with the mutation status, the apparent explanation was tumour mosaicism (see results). Thus, immunohistochemistry seems to agree with K-ras and p53 mutation status in most cases. It must be pointed out, however, that this conclusion applies to patients where a mutation is present, but it may not necessarily be true for patients where mutation is absent (we did not systematically study these patients because our primary aim was not to evaluate the suitability of immunohistochemistry in revealing K-ras and p53 mutations).

In summary, we conclude that rectal tumours in Finnish women have some characteristic features that seem to be uncommon in other human tumours, colon cancer included, as judged by comparison with the current data base. In particular, we found that in a high proportion of patients $(14 \%)$, rectal tumours seem to contain small subclones of tumour cells that display otherwise extremely rare mutations at codons 110 and 232 of the p53 gene. Apparently, these mutations must be late changes in tumour progression. Another relatively unique property of cancer of the rectum seems to be the low frequency of K-ras mutations (about 20\%). Finally, we also found a strong positive correlation between the age of the patient at diagnosis and p53 gene mutation frequency. Thus, it appears that the aetiological factors are different in cancers of the colon and rectum. We speculate that the risk factors in rectal cancers include an unidentified genetic factor common in Finland.

1 Harris CC, Hollstein M. Clinical implications of the p53 tumour-suppressor gene. N Engl f Med 1993;329:131827

2 Greenblatt MS, Bennett WP, Hollstein M, et al. Mutations in the p53 tumor suppressor gene: clues to cancer etiology and molecular pathogenesis. Cancer Res 1994;55:485578 .

3 Bennett WP. Does radiation cause molecular signatures? In: Boice JD, Jr, ed. Implications of new data on radiation cancer Bethesda, USA: National Council

4 Hainaut P, Hernandez T, Robinson A, et al. IARC database of p53 gene mutations in human tumors and cell lines: updated compilation, revised formats and new visualisation tools. Nucleic Acids Res 1998;26:205-13.

5 Fearon ER, Vogelstein B. A genetic model for colorectal tumorigenesis. Cell 1990;61:759-67.

6 Breivik J, Meling GI, Spurkland A, et al. K-ras mutation in colorectal cancer: relations to patient age, sex and tumour location. Br F Cancer 1994; 69:367-71.

7 Ilyas M, Tomlinson IP. Genetic pathways in colorectal cancer. Histopathology 1996;28:389-99.

8 Hakulinen T, Kenward M, Luostarinen T, et al. Cancer in Finland in 1954-2008. Incidence, mortality and prevalence by region. Helsinki: Finnish Foundation for Cancer Research, 1989.

9 Bufill JA. Colorectal cancer: evidence for distinct genetic categories based on proximal or distal tumor location. Ann categories based on proximal
Intern Med 1990;113:779-88.

10 Potter JD. Nutrition and colorectal cancer. Cancer Causes Control 1996; 7:127-46.

1 Rytömaa T, Servomaa K, Kiuru A, et al. Molecular epidemiological study of human rectal cancer induced by radiotherapy. Radioprotection 1997;32:257-8.

12 Pukkala E, Vertio H. Syöpä Suomessa. Helsinki: Finnish cancer registry, 1994 [In Finnish.

13 Yanez L, Groffen J, Valenzuela DM. c-K-ras mutations in human carcinomas occur preferentially in codon 12 . Oncogene 1987;1:315-18.

14 Vogelstein B, Fearon ER, Hamilton SR, et al. Genetic alterations during colorectal-tumor development. $N$ Engl f Med 1988;319:525-32.

15 Bell SM, Scott N, Cross D, et al. Prognostic value of p53 overexpression and c-Ki-ras gene mutations in colorectal cancer. Gastroenterology 1993;104:57-64.

6 Kojima M, Konishi F, Tsukamoto $\mathrm{T}$, et al. Ki-ras point mutation in different types of colorectal carcinomas in early stages. Dis Colon Rectum 1997;40:161-7.

17 Hirvikoski P, Auvinen A, Servomaa K, et al. K-ras and p53 mutations and overexpression as prognostic factors in
female rectal carcinoma. Anticancer Res 1999;19:685-92.

18 Goh HS, Yao J, Smith DR. p53 point mutation and survival in colorectal cancer patients. Cancer Res 1995;55:521721 .

19 Servomaa K, Kiuru A, Grenman R, et al. p53 mutations associated with increased sensitivity to ionizing radiation in human head and neck cancer cell lines. Cell Prolif 1996;29: 
219-30.

20 Pekkola-Heino K, Servomaa K, Kiuru A, et al. Increased radiosensitivity is associated with p 53 mutations in cell lines derived from oral cavity carcinoma. Acta Otolaryngol (Stockh) 1996;116:341-4

21 Ichii S, Takeda S, Horii A, et al. Detailed analysis of genetic alterations in colorectal tumors from patients with and without familial adenomatous polyposis (FAP). Oncogene 1993;8:2399-405.

22 Hasegawa $\mathrm{H}$, Ueda $\mathrm{M}$, Watanabe $\mathrm{M}$, et al. K-ras gene mutations in early colorectal cancer ... flat elevated vs

polyp-forming cancer... Oncogene $1995 ; 10: 1413-16$.
23 Fearon ER, Vogelstein B. A genetic model for colorectal tumorigenesis. Cell 1990;61:759-67.

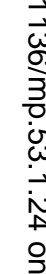

